\title{
Evaluation the effect of several anticancer drugs on Vietnamese breast cancer cells
}

\author{
Oanh Thi-Kieu Nguyen ${ }^{1,2,3, *}$
}

${ }^{1}$ Stem Cell Institute, VNUHCM

University of Science, Ho CHi Minh City, Viet Nam

${ }^{2}$ Laboratory of Stem Cell Research and Application, VNUHCM University of Science, Ho Chi Minh City, Viet Nam

${ }^{3}$ Laboratory of Cancer Research, VNUHCM University of Science, Ho Chi Minh City, Viet Nam

\section{Correspondence}

Oanh Thi-Kieu Nguyen, Stem Cell Institute, VNUHCM University of Science, Ho CHi Minh City, Viet Nam

Laboratory of Stem Cell Research and Application, VNUHCM University of Science, Ho Chi Minh City, Viet Nam

Laboratory of Cancer Research, VNUHCM University of Science, Ho Chi Minh City, Viet Nam

Email: oanhnguyen@sci.edu.vn

\section{History}

- Received: 03 August 2018

- Accepted: 15 September 2018

- Published: 28 September 2018

DOI :

https://doi.org/10.32508/stdj.v21i2.488

\section{Check for updates}

\section{Copyright}

(c) VNU-HCM Press. This is an openaccess article distributed under the terms of the Creative Commons Attribution 4.0 International license.

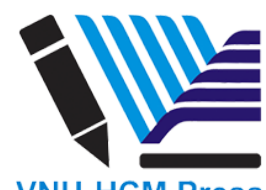

\begin{abstract}
In Viet Nam, data from Conference of Cancer organized by the Ministry of Health has shown that breast cancer is the most popular cancer in women. Current mainly treatments are surgery, chemotherapy, and radiotherapy. However, the rate of recurrence after five years was very high. One of the causes of high relapse is cancer cells develop multidrug-resistant (MDR) thus reduced the efficiency of treatments. In this research, MTT assay was used for measured cell viability of Vietnamese breast cancer cells (VNBRCA cells) and positive control MCF-7 cell lines after treatment with several anticancer drugs as Doxorubicin (DOX), Tamoxifen (TAM), Mitomycin C (MMC) in 48h. After that, cancer cells were treated at haft maximal inhibitory concentration $\left({ } C_{50}\right)$ of anticancer drug and observed cell morphology, apoptosis of cellular nuclear by AO/PI staining. $\mathrm{I}_{50}$ value of $\mathrm{VN}$ BRCA cells with DOX, TAM, MMC were $0.641 \pm 0.07 \mu \mathrm{M}, 4.639 \pm 0.933 \mu \mathrm{M}$ and $1.338 \pm 0.176 \mu \mathrm{M}$, respectively, which higher than $\mathrm{IC}_{50}$ of MCF-7 with DOX, TAM, MMC was $0.168 \pm 0.037 \mu \mathrm{M}, 7.085 \pm$ $0.87 \mu \mathrm{M}$ and $0.379 \pm 0.159 \mu \mathrm{M}$, respectively. The response of VNBRCA cells with several anticancer drugs as DOX, TAM, and MMC was lower than the response of MCF-7, therefore, it showed that the specific features of VNBRCA cells; from which develop specific treatments for Vietnamese breast cancer patients.
\end{abstract}

Key words: IC50, Anti-cancer drugs, Doxorubicin, Mitomycin C, Vietnamese breast cancer cells

\section{INTRODUCTION}

Breast cancer is the most frequently diagnosed cancer in Vietnamese women. In the last two decade from 2000 to 2010, the breast cancer incidence has more than double in age-standardized rate (ASR, the ratio per 100,000 people), particularly 13.8 in 2000 and 29.9 in 2010, approximately 12,533 new cases of breast cancer per year ${ }^{1}$. In 2008, the ASR of 100,000 women in Hanoi and Ho Chi Minh City respectively 29,7\% and $19.4 \%$ shown breast cancer still the most common cancer in Vietnamese women ${ }^{2}$. These are many causes of breast cancer in Vietnamese women, such as the age of first menarche and menopause, number of children, using hormone and daily exercise ${ }^{3}$. Breast tumors could be classified into many different subgroups according to their cell surface markers as the human epidermal growth factor receptor 2 (HER2), progesterone receptor (PR) or estrogen receptor (ER) ${ }^{4}$. A survey on 492 breast cancer patients at the National Cancer Hospital of Vietnam in Hanoi from January 2007 to August 2013 showed that $61.6 \%$ of cases were ER-positive, $58.5 \%$ of cases were PR-positive, 21.4\% of cases were Her2-positive, and $15 \%$ of cases were triple negative breast cancer (ERnegative, PR-negative, Her2-negative) ${ }^{5}$. The other survival data from Hue Central Hospital and the Cancer Registry in Ho Chi Minh City showed the survival rates at 1 year, 3 years and 5 years following diagnosis were $0.94,0.83$ and 0.74 respectively; and the prognostic factor for mortality of breast cancer patients were stage at diagnosis, health status, marital status, using hormone, education level ${ }^{6}$. Because severe problems of breast cancer, several methods were developed for the treatment, such as surgery, radiotherapy, chemotherapy, and hormone therapy. In cancer, surgery is the primary and most fundamental method both in the diagnosis and in cancer treatments. The type of surgery is based on cancer diagnosis, defined cancer states, remove a part or all of the tumor, e.g., the surgery in breast cancer treatment depends on the tumor location, size and other factors, the surgeon could use breast conserving or total mastectomy ${ }^{7}$. Chemotherapy is an effective therapy against various type of human cancer, besides that many cancer cells also develop multidrug-resistant (MDR), the most problems for successful cancer treatment ${ }^{8}$. Many drugs and therapies had been developed to cure breast cancer, such as Doxorubicin, Tamoxifen, Mitomycin C. Doxorubicin (DOX), is one of the most effective and broad-spectrum antibiotic, used in the treatment of a variety of hematology and 
solid malignancies, included leukemias, Hodgkin's and non-Hodgkin's lymphomas, breast, lung, ovarian and bladder cancers ${ }^{9-11}$. The major limiting factor of using DOX is the chronic cardiotoxicity because the high level of DOX could damage the cell membranes, cellular proteins (e.g., enzymes, structural, and receptors), and DNA that may lead to cellular apoptosis and cardiac dysfunction ${ }^{9}$.

Tamoxifen (TAM) is an antiestrogenic drug, which widely used for treating the patient who exhibits estrogen receptor-positive breast cancer ${ }^{12}$. TAM is a prodrug form that could be metabolized in cytochrome P450 through CYP2D6 and CYP3A4 isoforms to the active form, which called endoxifen ${ }^{13,14}$. TAM could shrink a large, hormone receptor-positive breast tumor, and used both in premenopausal and postmenopausal women who can't cure with an aromatase inhibitor ${ }^{7,15,16}$

Mitomycin C (MMC) is the broad-spectrum agent in tumor resistance that targets explicitly in CpG sequences. MMC was able to inhibit DNA synthesis through binding to the amino quinone group. MMC interacted with DNA could form the cross link between two complementary of the DNA strand, which could cause inhibited DNA synthesis and DNA replication $^{17}$.

However, breast cancer has become resistant to treatment, this means that chemotherapy or radiotherapy could not be affected on all cancer cells, most of the cancer cells may have killed, but some of them were either not changed and survive after treatments. Moreover, chemotherapeutic drugs are also toxic with normal cells, which caused several side effects to the patients. Therefore, the rate of tumor recurrence after five years in breast cancer patients still increase, maybe cancer cells had self-changed to resistant with a chemotherapeutic.

The purpose of this research is to investigate the effects of several common anticancer drugs in Vietnam breast cancer cells (VNBRCA) through evaluating the half-maximal inhibition concentrations $\left(\mathrm{IC}_{50}\right)$, cell viability of cells after anti-cancer drugs treatment.

\section{METHODS}

\section{Cell lines and chemicals}

Human breast cancer cell line MCF-7 were purchased from the American Type Culture Collection. Vietnam breast cancer cells were supported by Stem Cell Institute, VNUHCM-University of Science, Viet Nam. Cancer cells were cultured in DMEM/F12 (Dulbecco's Modified Eagle's Medium/Ham F12) containing 10\% FBS (Fetal Bovine Serum, Invitrogen, CA, USA), 1\% antibiotic 100X (Invitrogen, CA, USA) at $37^{\circ} \mathrm{C}$ with an atmosphere of $5 \% \mathrm{CO}_{2}$. Doxorubicin (DOX) was purchased from Sigma-Aldrich (44583, CAS number 25316-40-9) and Mitomycin C was purchased from Kyowa Hakko Kogyo Co were dissolved in aqueous, Tamoxifen was purchased from Sigma-Aldrich (T5648, CAS number 10540-29-1) and dissolved in dimethyl sulfoxide (DMSO). These anticancer drugs were used for MTT viability assay.

\section{MTT viability assay}

Cytotoxic effect on cancer cells was determined by using MTT assay after $48 \mathrm{~h}$ treatment with anticancer drugs. Cancer cells were seeded onto 96 -well plates at density $5.10^{3}$ cells/well, cultured at $37^{\circ} \mathrm{C}, 5 \% \mathrm{CO}_{2}$ for $24 \mathrm{~h}$. Then, cancer cells were added with anticancer drugs at several concentrations $0-20 \mathrm{M}$ and triple replicate in each concentration. Following incubation $48 \mathrm{~h}$ at $37^{\circ} \mathrm{C} 5 \% \mathrm{CO}_{2}$, added $10 \mu L$ of MTT solution $(5 \mathrm{mg} / \mathrm{ml})$ into $100 \mu \mathrm{L}$ cell culture medium and incubated at $37^{\circ} \mathrm{C}, 5 \% \mathrm{CO}_{2}$. After 4 hours incubation, treated plates were centrifuged $500 \mathrm{~g}$ in $5 \mathrm{~min}$ utes, then removed the supernatant, added $100 \mu \mathrm{L}$ of DMSO to each well and shaken for ten mins (horizontal shaker) to dissolve the violet formazan crystals. The optical density (OD) was measured by using Beckman Coulter DTX 880 Multimode Detector at $495 \mathrm{~nm}$. The cytotoxic efficiency of anticancer drugs was specified by using the percentage of cell viability at several different concentration. The $\mathrm{IC}_{50}$ value was determined in the cell viability by GraphPad Prism 7.0 software. Each experiment was repeated in triplicate. Cell viability (\%) = Mean OD/Control OD x 100\%

\section{AO/PI staining assay}

Acridine Orange/Propidium Iodine (AO/PI) are dyes which bind to nucleic acid and used to observe live/dead cells. Acridine Orange (AO) is a membrane permeable nuclear dye that stains all nucleated cells both in live and dead cells and emits the green fluorescence. While Propidium Iodine (PI) is membrane impermeable nuclear dye that stains dead cells to generate the red fluorescence. For AO/PI double staining, samples were combined with AO/PI Staining Working Solution at ratio 1:1, then cells were observed under a fluorescence microscope. Live cells will emit the green fluorescence (at the excitation $485 \mathrm{~nm}$ and the emission $548 \mathrm{~nm}$ ), and dead cells will generate the red fluorescence (at the excitation $520 \mathrm{~nm}$ and the emission $590 \mathrm{~nm})$. 


\section{Statistical analysis}

The result of experiments was handled by using the GraphPad Prism 7.04 software. The data are performed in three independent experiments.

\section{RESULTS}

The IC $_{50}$ values (50\% inhibitory concentration) of anticancer drugs in MCF-7 cells and VNBRCA cells

The cytotoxic efficiency of anticancer drugs as Doxorubicin, Tamoxifen, Mitomycin C against breast cancer cell lines was measured by using MTT assay. After $48 \mathrm{~h}$ treatment with anticancer-drugs at different doses, cell viability of cancer cells was determined. Results of cytotoxicity assay were presented in Figure 1and Table 1.

DOX could inhibit the growth of MCF-7 cells and VNBRCA cells. These cancer cells were treated at the concentration of half dilutions $2,1,0.5,0.25,0.125$ and $0.0625 \mu \mathrm{M}$ for $48 \mathrm{~h}$ and achieved inhibition of the cell growth compared with non-treated cells as a negative control. The cell viability following DOX treatment are shown in Figure 1A, the $\mathrm{IC}_{50}$ value of DOX against MCF7 cells and VNBRCA cells was measured from the cell viability by GraphPad Prism 7.0 (Figure 1B) as $0.168 \pm 0.037 \mu \mathrm{M}$ and $0.641 \pm 0.07$ $\mu \mathrm{M}$, respectively (Table 1). The $\mathrm{IC}_{50}$ value of DOX on MCF-7 was similar to the result of Chen et al. (2015) was $0.11 \pm 0.012 \mu \mathrm{M}^{18}$.

To examine the inhibition of the growth on cancer cells, these MCF-7 and VNBRCA cells were treated with TAM at the concentration of half dilutions 20, 10, $5,2.5,1.25$ and $0.625 \mu \mathrm{M}$ for $48 \mathrm{~h}$, with non-treated cells as a negative control. The cell viability of TAM was shown in (Figure 1C), and the $\mathrm{IC}_{50}$ value of TAM was $7.085 \pm 0.87 \mu \mathrm{M}$ and $4.639 \pm 0.933 \mu \mathrm{M}$ in MCF-7 and VNBRCA cells, respectively (Figure 1D, Table 1). $\mathrm{IC}_{50}$ value of TAM against MCF-7 is 4,639 $\pm 0,933$ $\mu \mathrm{M}$, were similarly to result from Hassan et al. with $\mathrm{IC}_{50}$ of TAM on MCF-7 is $4,506 \mu \mathrm{g} / \mathrm{ml}$

To investigate the inhibitory effect of MMC, these cancer cells were treated with anticancer drug MMC at the concentration of half dilutions 8, 4, 2, 1, 0.5 and $0.25 \mu \mathrm{M}$ for $48 \mathrm{~h}$, with non-treated cells as a negative control. The result of MTT assay shows the cell viability following MMC treatment (Figure 1E), and the $\mathrm{IC}_{50}$ value in MCF-7 cells and VNBRCA cells (Figure 1F) respectively were $0.379 \pm 0.159 \mu \mathrm{M}$ and $1.338 \pm 0.176 \mu \mathrm{M}$ (Table 1).

Table 1showed the concentration of DOX, TAM and MMC required to inhibit MCF-7 and VNBRCA cell proliferation by $50 \%$. Figure 2 showed the graph of Ttest compare the effect of anticancer drugs between cancer cell lines and the morphology of cells after treated with anticancer drugs at the $\mathrm{IC}_{50}$ value.

Breast cancer cells were treated with anticancer drugs at the $\mathrm{IC}_{50}$ values. The statistically different between two cell lines were shown in Figure 3. Morphological observation of cancer cells after treatment (Figure 2) showed the effect of cancer drugs on cell morphology in cell culture. In DOX and MMC treatment, the sizes of cells were larger than control, while in TAM treatment, cells were smaller, apoptotic cells had a round shape and floated in media culture.

\section{Apoptosis of cancer cells after treatment with anticancer drugs at $\mathbf{I C _ { 5 0 }}$}

Induction of apoptosis on cancer cells was also investigated by microscopic analysis of AO/PI double staining assay. Nuclei observation was performed to observe the efficiency of anticancer drugs which have the ability to induce apoptosis. Figure 3and Figure 4showed the untreated control and the anticancer drug-treated on MCF-7 and VNBRCA cells, respectively. With the green fluorescence, Acridine Orange (AO) showed all the nuclear cells, while in red fluorescence, only apoptotic cells could expose the light. Disintegrated nuclei appeared in the fluorescent images when cells were treated with anticancer drugs indicated that treated cells were undergoing apoptosis, while there were a few of dead cells in the control sample and those cells did not show the abnormal in nuclei DNA.

\section{DISCUSSION}

Breast cancer is popular cancer in woman, despite the evolution of treatments, it is still the primary cause of death in female cancer patients. Doxorubicin, Tamoxifen, and Mitomycin C are a widely used drug for treating breast cancer patients. The primary mechanism in the response of cancer cells with chemotherapy is the activation of apoptotic pathways. The cell viability is an important parameter and is directly associated with the cytotoxic effects of a drug ${ }^{19}$.

In this research, DOX and MMC caused apoptosis both in MCF-7 and VNBRCA cells, the $\mathrm{IC}_{50}$ values of DOX and MMC on VNBRCA cells were higher than on MCF-7 cells (Table 1). Therefore, therapeutic doses of DOX and MMC used in VNBRCA cells were higher in the treatment of Vietnam breast cancer patients. DOX is a broad spectrums antibiotic used in the treatment of cancers, which could inhibit the DNA synthesis by intercalating into complementary 


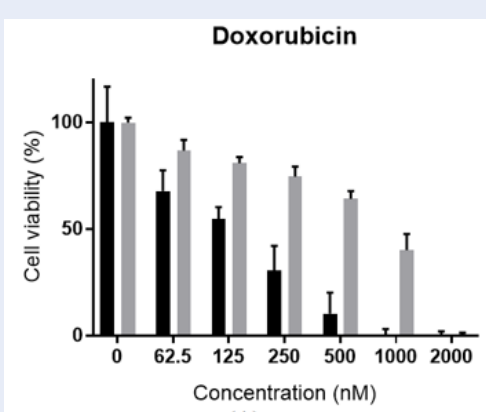

(A)

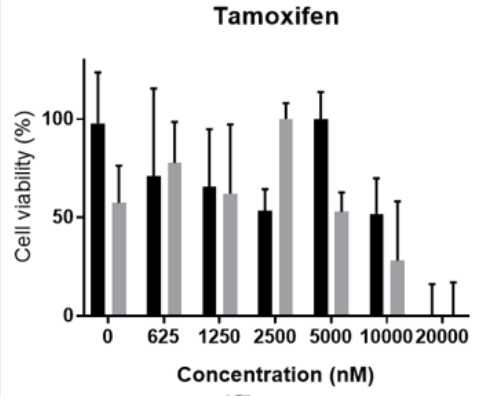

(C)

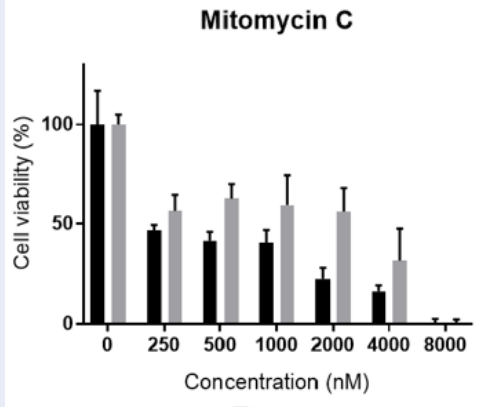

(E)
Doxorubicin
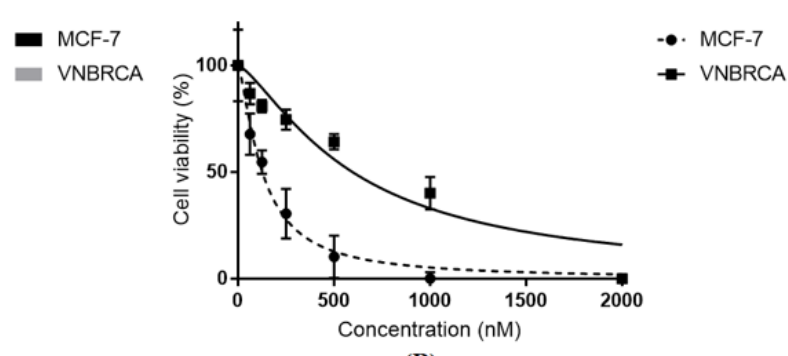

(B)

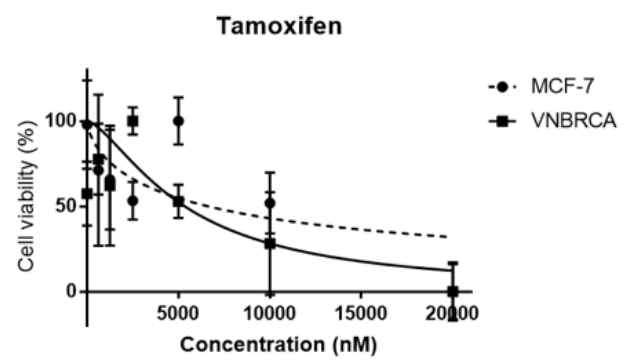

(D)

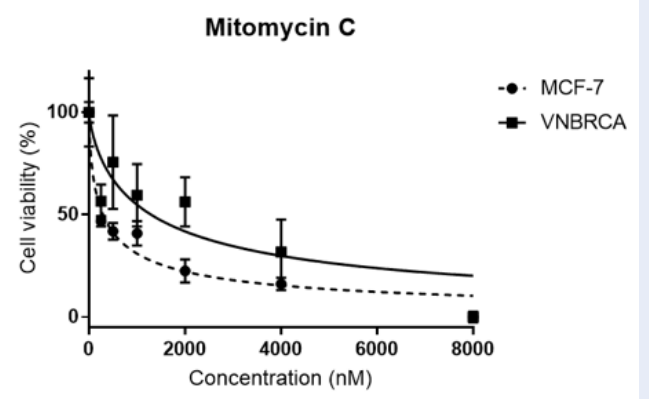

(F)

Figure 1: Cell viability of MCF-7 and VNBRCA1 after treatment with various concentration of anticancer drugs DOX (A, B), TAM (C, D), MMC (E, F).

Table 1: The IC50 value of both cell lines with anti-cancer drugs

\begin{tabular}{lcccc} 
& \multicolumn{2}{c}{ MCF-7 } & \multicolumn{2}{c}{ VNBRCA1 } \\
& IC $_{50}(\mu \mathbf{M})$ & Standard deviation & IC $_{50}(\mu \mathbf{M})$ & Standard deviation \\
Doxorubicin & 0.168 & 0.037 & $0.641^{* * *}$ & 0.07 \\
Tamoxifen & 7.085 & 0.87 & $4.639^{*}$ & 0.933 \\
Mitomycin C & 0.379 & 0.159 & $1.338^{* *}$ & 0.176 \\
\hline
\end{tabular}

When compared with MCF-7 cells, the $\mathrm{IC}_{50}$ value of DOX, MMC were higher, and the IC50 value of TAM was lower in VNBRCA ${ }^{*} \mathrm{p}<0.05$, ${ }^{* *} \mathrm{p}<0.01,{ }^{* * *} \mathrm{p}<0.001$ 

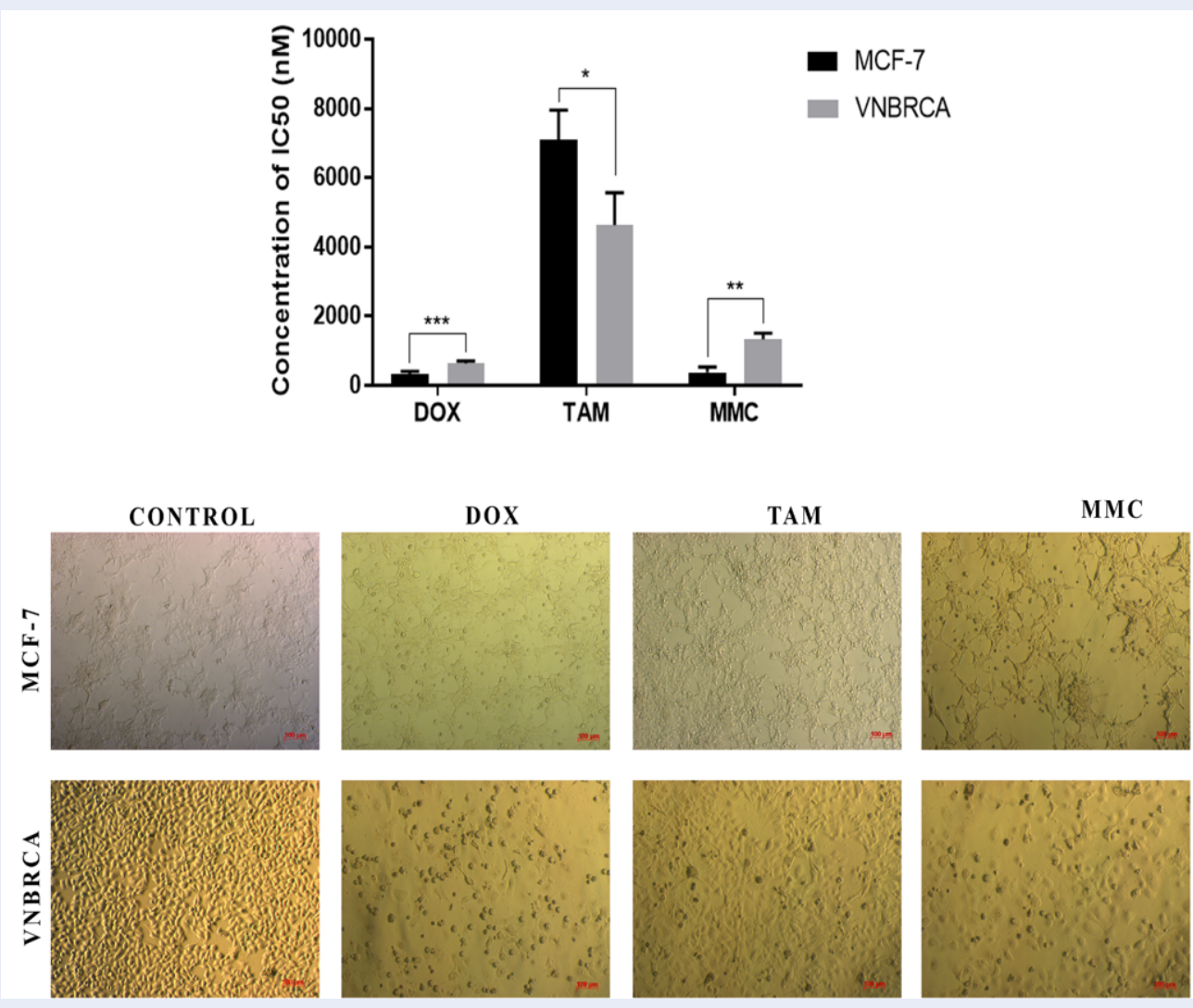

Figure 2: Morphology of cancer cells was cultured with anticancer drugs at IC $\mathrm{C}_{50}$ values.

of DNA-strands and inhibit DNA topoisomerase $\mathrm{II}^{20}$. Mitomycin C is an antitumor antibiotic which could cause apoptosis through inhibition of DNA synthesis, initiation mutagenesis caused by DNA repair events. In culture, these compounds had decreased the cell viability at increasing concentrations, made the disorganization of the cell nucleus and produced giant cells (Figure 2). DOX and MMC are chemotherapeutic agents whose efficiency is limited by severe side effect, e.g., the cardiotoxicity of $\mathrm{DOX}^{9}$ and myelosuppression of $\mathrm{MMC}^{21}$. Besides, MCF-7 cells exposed with DOX low-doses could develop the multidrug resistance and the upregulation of MDR1, CD44st, NFprotein and $\mathrm{mRNA}^{22}$. These are several factors which could be responsible for broad-spectrum MDR, included over expression of the membrane-bound ATPbinding cassette transporters (ABC proteins) such as P-glycoprotein (P-gp), breast cancer resistance protein (BCRP), MDR-1 and MDR-2. This protein could prevent the accumulation of the drug in intracellular or modify the distribution of anticancer drugs in cancer cells ${ }^{8,11}$. Some research had demonstrated that natural antioxidants might be useful in reducing the cardiotoxicity in patients who treated with doxorubicin ${ }^{9}$. In the future, novel chemotherapy should design to increase the role of natural products in combination with DOX on cancer therapy and to minimize side effects of DOX.

The cytotoxicity effect of TAM on VNBRCA cells were higher than on breast cancer cells MCF-7, so the $\mathrm{IC}_{50}$ value of TAM on VNBRCA cells was lower than on MCF-7 cells (Table 1). As in the survey at the National Cancer Hospital of Vietnam in Hanoi showed that $61.6 \%$ of Vietnam breast cancer cases were ERpositive $^{5}$, so TAM is an appropriate anticancer drug for Vietnam breast cancer patients. TAM can induce apoptosis of cancer cells via the involvement of a mitochondria-dependent pathway, the amendment of signaling protein such as protein kinase $\mathrm{C}$, and the up-regulation of $\mathrm{p} 53^{23}$. The activity of caspase- 9 was direct correlates with the cytotoxic effects of TAM ${ }^{20}$. TAM could be affected on the cell membrane, caused the rapid changes in membrane permeability, offers a very long period of protection after surgery remove tumors and could bring more benefit to breast cancer prevention ${ }^{15}$. Although TAM is one of the most wide 


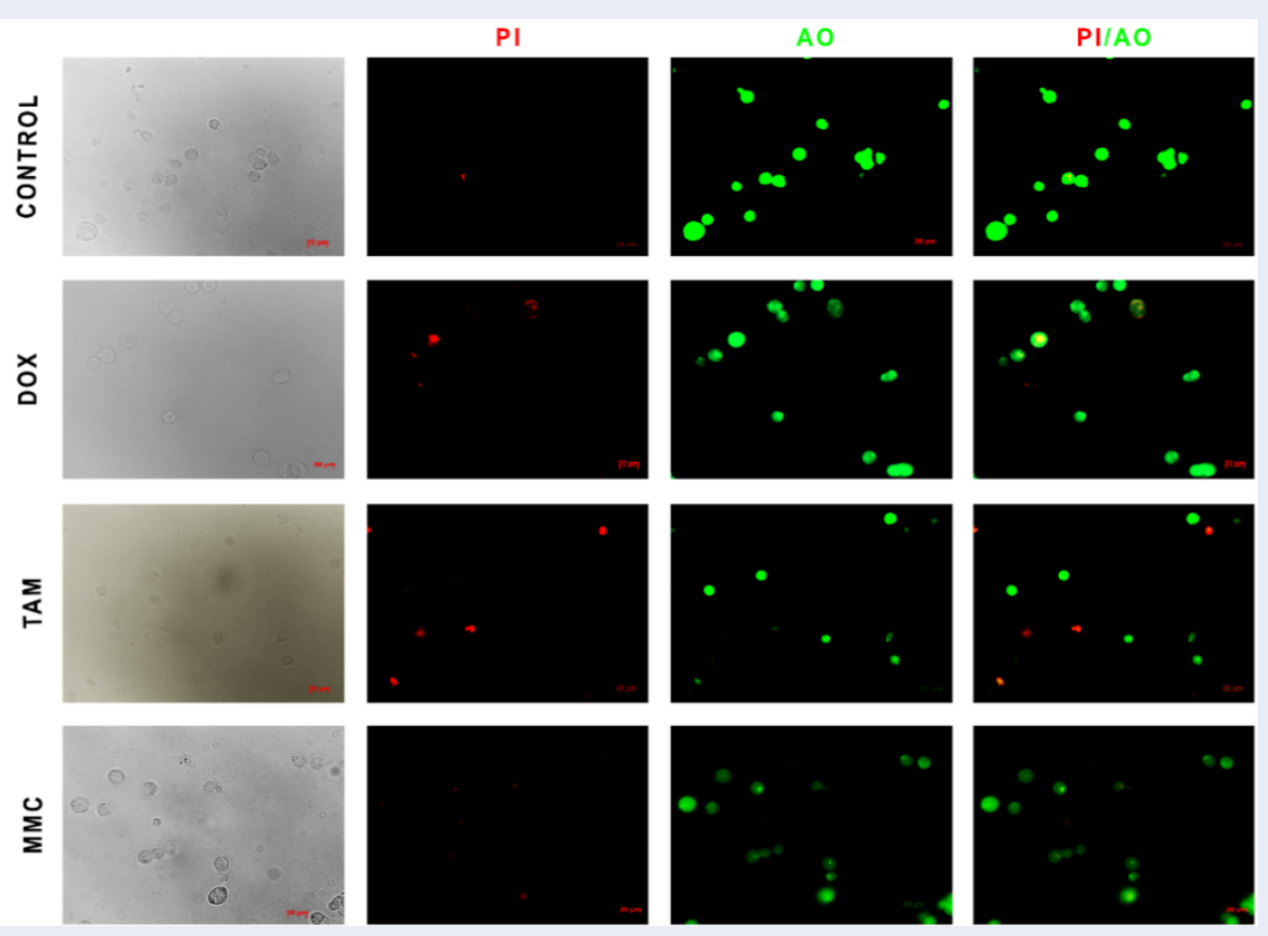

Figure 3: Fluorescent micrographs of AO/PI double-stained MCF-7 cells after $48 \mathrm{~h}$ treatment with anticancer drugs.

drugs in breast cancer treatments, many patients still relapsed after long-term TAM treatment ${ }^{23}$. These are several reasons interpreted why several people could not get the full benefit of TAM as a flaw in the CYP2D6 enzyme, an enzyme to convert TAM into its active form and medications which block the effectiveness of this enzyme. One of the side effects of TAM is could enhance the high risk of endometrial lesions, such as hyperplasia, carcinoma, sarcoma in breast cancer patients $^{24}$. Based on these results, choosing the appropriate chemotherapy should be conformed to cellular characteristics as cell surface marker, molecular features...Each cancer cell lines have different elements would have a dose of anticancer drugs which offer the excellent efficiency, so developing the individual therapy is an innovative trend to bring useful treatment for cancer patients.

\section{CONCLUSION}

Vietnam breast cancer cells were less sensitive to anticancer drugs which evaluated in this work. MTT assay result and microscope images indicated that the cytotoxicity of the extract was dose-dependent. With DOX and MMC, VNBRCA cells were less sensitive than MCF-7 cells, means that high doses of these anticancer drugs would be treated in breast cancer patients, which would cause the high cytotoxicity and more dramatic side effects. With TAM, VNBRCA cells were more sensitive, produced by ER-positive cancer cells. Breast cancer patients need to identify cell surface markers, which could find the appropriate therapy, help to increase the effect of anticancer drugs, reduce the side effect of chemotherapy and the low cost of treatment. The primary cause of therapeutic failure in breast cancer patients is multi-drug resistance to cytotoxic chemotherapy, so using a reasonable dose of anticancer drugs may help to cure and prevent the tumor recurrence, improve the survival rate. Besides that, breast self-examination, screening programs, and new treatments should be encouraged and increased the life expectancy of Vietnamese breast cancer women.

\section{COMPETING INTERESTS}

The authors hereby declare there are no conflicts of interest associated with this work.

\section{ACKNOWLEDGMENTS}

Vietnam National University funded this experiment, Ho Chi Minh City, Viet Nam under grant number A2015-18-01/HD-KHCN and VNUHCM-University of Science, Ho Chi Minh City, Viet Nam with grant number T2017-42. The author also thanks to Stem Cell Institute for helping to complete this project. 


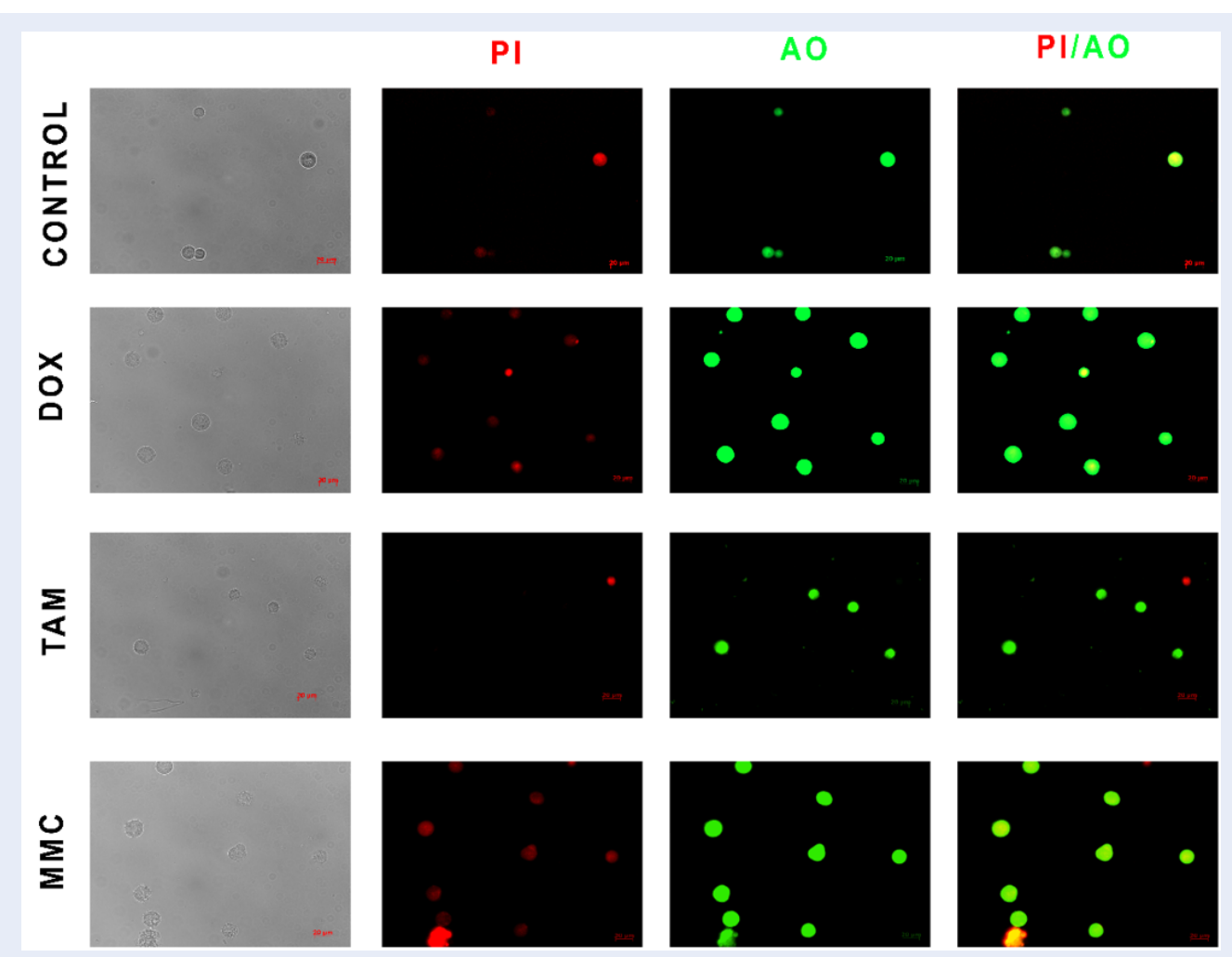

Figure 4: Fluorescent micrographs of AO/PI double-stained VNBRCA cells after 48h treatment with anticancer drugs.

\section{ABBREVIATIONS}

IC50: the half-maximal inhibition concentrations MTT: 3-(4,5-dimethythiazol-2-yl)-2,5diphenyltetrazolium bromide

DOX: doxorubicin

TAM: tamoxifen

MMC: mitomycin C

\section{REFERENCES}

1. Jenkins C, Minh LN, Anh TT, Ngan TT, Tuan NT, Giang KB. Breast cancer services in Vietnam: a scoping review. Global Health Action. 2018;11:1435344. Available from: Doi:10.1080/ 16549716.2018.1435344.

2. Trieu PD, Mello-Thoms C, Brennan PC. Female breast cancer in Vietnam: a comparison across Asian specific regions. Cancer Biology \& Medicine. 2015;12:238-45.

3. Trieu PD, Mello-Thoms C, Peat JK, Do TD, Brennan PC. Risk Factors of Female Breast Cancer in Vietnam: A Case-Control Study. Cancer Research and Treatment. 2017;49:990-1000. Available from: DOI:10.4143/crt.2016.488.

4. Holliday DL, Speirs V. Choosing the right cell line for breast cancer research. Breast Cancer Research. 2011;13:215. Available from: DOI:10.1186/bcr2889.

5. Nguyen J, Le QH, Duong BH, Sun P, Pham HT, Ta VT. A Matched Case-Control Study of Risk Factors for Breast Cancer Risk in Vietnam. International Journal of Breast Cancer. 2016;2016:7164623. Available from: Doi:10.1155/2016/ 7164623.

6. Lan NH, Laohasiriwong W, Stewart JF. Survival probability and prognostic factors for breast cancer patients in Vietnam.
Global Health Action. 2013;6:1-9. Available from: DOI:10. 3402/gha.v6i0.18860.

7. Yang G, Nowsheen S, Aziz K, Georgakilas AG. Toxicity and adverse effects of Tamoxifen and other anti-estrogen drugs. Pharmacology \& Therapeutics. 2013;139:392-404. Available from: DOI:10.1016/j.pharmthera.2013.05.005.

8. De U, Chun P, Choi WS, Lee BM, Kim ND, Moon HR. A novel anthracene derivative, MHY412, induces apoptosis in doxorubicin-resistant MCF-7/Adr human breast cancer cells through cell cycle arrest and downregulation of $\mathrm{P}$ glycoprotein expression. International Journal of Oncology. 2014;44:167-76. Available from: DOI:10.3892/ijo.2013.2160.

9. Wattanapitayakul SK, Chularojmontri L, Herunsalee A, Charuchongkolwongse S, Niumsakul S, Bauer JA. Screening of antioxidants from medicinal plants for cardioprotective effect against doxorubicin toxicity. Basic \& Clinical Pharmacology \& Toxicology. 2005;96:80-7. Available from: DOI:10.1111/j. 1742-7843.2005.pto960112.x.

10. Osman AM, Bayoumi HM, Al-Harthi SE, Damanhouri ZA, Elshal MF. Modulation of doxorubicin cytotoxicity by resveratrol in a human breast cancer cell line. Cancer Cell International. 2012;12:47. Available from: Doi:10.1186/1475-2867-12-47.

11. Wang $X$, Teng $Z$, Wang $H$, Wang $C$, Liu $Y$, Tang $Y$. Increasing the cytotoxicity of doxorubicin in breast cancer MCF-7 cells with multidrug resistance using a mesoporous silica nanoparticle drug delivery system. International Journal of Clinical and Experimental Pathology. 2014;7:1337-47.

12. Sporn MB. Agents for Chemoprevention and Their Mechanism of Action. Holland-Frei Cancer Medicine; 2003.

13. Goetz MP, Rae JM, Suman VJ, Safgren SL, Ames MM, Visscher DW. Pharmacogenetics of tamoxifen biotransformation is as sociated with clinical outcomes of efficacy and hot flashes. 
Journal of Clinical Oncology. 2005;23:9312-8. Available from: Doi:10.1200/jco.2005.03.3266.

14. Yuan $S$, Sun $Q$, Chen $Y$, Liao J. A PharmacokineticPharmacodynamic Model of Tamoxifen and Endoxifen to Predict Their Distribution and Effects on Inhibition of Tumor Growth. Drug Metabolism Letters. 2017;11:93-101.

15. Cuzick J, Sestak I, Cawthorn S, Hamed H, Holli K, and AH. Tamoxifen for prevention of breast cancer: extended longterm follow-up of the IBIS-I breast cancer prevention trial. The Lancet Oncology. 2015;16:67-75. Available from: Doi: 10.1016/s1470-2045(14)71171-4.

16. Yu F, Bender $\mathrm{W}$. The mechanism of tamoxifen in breast cancer prevention; 2001.

17. Warren AJ, Mustra DJ, Hamilton JW. Detection of mitomycin C-DNA adducts in human breast cancer cells grown in culture, as xenografted tumors in nude mice, and in biopsies of human breast cancer patient tumors as determined by (32)Ppostlabeling. Clinical Cancer Research. 2001;7:1033-42.

18. Chen T, Wang C, Liu Q, Meng Q, Sun H, Huo X. Dasatinib reverses the multidrug resistance of breast cancer MCF-7 cells to doxorubicin by downregulating P-gp expression via inhibiting the activation of ERK signaling pathway. Cancer Biology \& Therapy. 2015;16:106-14. Available from: Doi:10.4161/ 15384047.2014.987062.

19. Hassan F, Mohammed G, El-Hiti GA, Alshanon A, Yousif E. Cy- totoxic effects of tamoxifen in breast cancer cells. Journal of Unexplored Medical Data. 2018;3:3. Available from: Doi: 10.20517/2572-8180.2017.25.

20. Yang F, Teves SS, Kemp CJ, Henikoff S. Doxorubicin, DNA torsion, and chromatin dynamics. Biochimica et Biophysica Acta (BBA). Revue Canadienne. 2014;1845:84-9.

21. Shuhendler AJ, O'Brien PJ, Rauth AM, Wu XY. On the synergistic effect of doxorubicin and mitomycin $C$ against breast cancer cells. Drug Metabolism and Drug Interactions. 2007;22:201-33. Available from: Doi:10.1515/dmdi.2007.22.4 201.

22. Fang XJ, Jiang $H$, Zhu YQ, Zhang LY, Fan QH, Tian Y. Doxorubicin induces drug resistance and expression of the nove CD44st via NF- $\kappa$ B in human breast cancer MCF-7 cells. Oncology Reports. 2014;31:2735-42. Available from: DOI:10.3892/ or.2014.3131.

23. Motawi TK, Abdelazim SA, Darwish HA, Elbaz EM, Shouman SA. Modulation of Tamoxifen Cytotoxicity by Caffeic Acid Phenethyl Ester in MCF-7 Breast Cancer Cells. Oxidative Medicine and Cellular Longevity. 2016;2016:3017108. Available from: Doi:10.1155/2016/3017108.

24. Hu R, Hilakivi-Clarke L, Clarke R. Molecular mechanisms of tamoxifen-associated endometrial cancer (Review). Oncology Letters. 2015;9:1495-501. Available from: DOI:10.3892/ ol.2015.2962. 